Pak. J. Agri. Sci., Vol. 55(3), 513-519; 2018

ISSN (Print) 0552-9034, ISSN (Online) 2076-0906

DOI: $10.21162 / P A K J A S / 18.5149$

http://www.pakjas.com.pk

\title{
GENE ACTION ARRAY RELATED TO MORPHO-PHYSIOLOGICAL TRAITS USING POPULATION GENETICS IN Triticum aestivum L.
}

\author{
Rana Haroon Maqsood ${ }^{1 *}$, Ihsan Khaliq ${ }^{1}$, Muhammad Kashif ${ }^{1}$ and Nisar Ahmed ${ }^{2}$ \\ ${ }^{1}$ Department of Plant Breeding \& Genetics, University of Agriculture, Faisalabad, Pakistan; ${ }^{2}$ Centre of Agricultural \\ Biochemistry \& Biotechnology, University of Agriculture, Faisalabad, Pakistan. \\ "Corresponding author's email: rana.haroon1@gmail.com
}

\begin{abstract}
Drought is a major constraint in grain production of bread wheat. Drought tolerant Pakistani line Chakawal-50 and drought susceptible line 9436 was crossed to develop $F_{1}, F_{2}$ and backcross generations. Genetic analysis was conducted for different traits (Stomatal conductance, photosynthetic rate, excised leaf water loss, relative water content, plant height, number of grains per spike and grain yield per plant). Presence of additive, dominance and epistatic components were identified for all traits under study. Gene action was found complex in nature except for plant height. Selection should be done in later generations for improvement of traits with complex gene action. Where selection in early generations was suggested due to significant additive component for plant height. Number of grains per spike showed medium while remaining traits showed high broad sense heritability. Number of grains per spike and stomatal conductance showed low while remaining traits showed medium narrow sense heritability. Relative water contents and number of grains per spike showed high while remaining traits showed low genetic advance. It was also suggested that selection in $\mathrm{F}_{2}$ and succeeding populations for variety development would result in improvement of all traits except for excised leaf water loss and plant height. In these traits hybrid breeding was suggested due to high heritability and low genetic advance.
\end{abstract}

Keywords: Bread wheat, photosynthetic rate, heritability, epistasis, genetic advance

\section{INTRODUCTION}

Wheat, a rich source of energy, is most important cereal crop in world which provides more than $50 \%$ calories of daily intake to the world population (FAO, 2015). Wheat is sensitive to abiotic stresses. Under water limited conditions plants cannot perform normal physiological activities thus resulting in loss of yield (Said, 2014). Availability of useable irrigation water is decreasing in inverse proportion to an everincreasing human population (Vorosmarty et al., 2000). To keep up with increasing population, wheat should be tailored against water scarce environments.

Plant response to drought is a complex phenomenon (Reddy et al., 2004). Drought affects plant osmotic potential and ionic equilibrium resulting in complete or partial blockage of vital physiological processes such as photosynthesis. Photosynthetic rate is primary physiological process which indicates the amount of $\mathrm{CO}_{2}$ consumed and glucose produced by the plant. In the absence of glucose plant cannot produce energy resulting in death of plant cells (Reddy et al., 2004).

Water stress also affects plant at different levels of structural organization. Limited water supply causes certain morphological changes in plants like wilting and shrinking of leaves, elongation of roots but reduction in root thickness, reduction in stomata counting, thickening of cell wall of leaves, deposition of epicuticular wax causing reflection of sunlight, development of conductive system, large vessels increased, early maturity, senescence and tube leaves formation in cereals. To maintain plant's internal water supply, roots elongate in the soil causing increase in root to shoot ratio due to increase in the production of abscisic acid (ABA) in the roots (Chandrasekar et al., 2000).

So, keeping in view the scarcity of water, it is need of time to develop plants which can perform better under water scarce conditions (Novoselovic et al., 2004). To develop drought tolerant cultivar, knowledge about genes which are controlling the principle parameters and are vital for production under drought conditions is important (Tonk et al., 2011).

Genetic analysis related to certain traits in wheat has already been reported for stomatal conductance (Rebetzke et al., 2003b; Farshadfar et al., 2013a), photosynthetic rate (Simon, 1994; Rebetzke et al., 2006b), excised leaf water loss (Farshadfar et al., 2001b), Relative water content (Farshadfar et al., 2001b; Golparvar et al., 2006b; Farshadfar et al., 2013b) and grain yield per plant (Khan et al., 2000; Akhtar and Chowdhry, 2006; Ullah et al., 2010; Rashid et al., 2012). Selection efficiency in segregating populations can be estimated using heritability and genetic advance. Yield improvement can be done by improving selection efficiency. Simon (1994) showed high heritability estimates for number of grains per spike and grain yield per plant. Rebetzke $e t$ al. (2006b) revealed high genetic advance for relative water contents. Visscher et al. (2008) showed low heritability and 
genetic advance for excised leaf water loss and plant height. While Magda and El-Rahman (2013) showed high heritability for relative water contents. Correlation studies revealed positive correlation for different traits with yield under water stress conditions (Condon et al., 1990; Khan et al., 2003; Rauf et al., 2007; Akram et al., 2008).

Genetic studies can be carried out using certain biometrical techniques like Generation Means Analysis (GMA) (Mather and Jinks, 1982). In this study GMA experiment consisted of six populations $\left(\mathrm{P}_{1}, \mathrm{P}_{2}, \mathrm{~F}_{1}, \mathrm{~F}_{2}, \mathrm{BC}_{1}\right.$ and $\left.\mathrm{BC}_{2}\right)$ from a cross to find the gene action under water scarce conditions. The objectives of this study were to explore genetic mechanism involved in water stress tolerance and estimate heritability and genetic advance for all traits under study.

\section{MATERIALS AND METHODS}

Field layout and plant material: Sixty genotypes were screened for relative water contents. Chakwal-50 ( $\mathrm{P}_{1}$ and tolerant) and $9436\left(\mathrm{P}_{2}\right.$ and susceptible) were selected and crossed to develop $F_{1}$ in 2011-12 in the Dept. of Plant Breeding and Genetics, University of Agriculture, Faisalabad. In 2012-13 $F_{2}$ and Backcross populations were developed. Line 9436 was developed by crossing Inqlab $91 \times$ WLRG1 (1-8) 1993-94. The parents and their respective $F_{1}, F_{2}$ and backcross populations of Chakwal-50 $\times 9436$ were grown in the field using split plot under randomized complete block design (RCBD) with three replications using normal and water stress conditions during growing season 2013-14.

Stress levels were allotted to main plots while treatment levels were allotted to subplots. There were two stress levels (Normal four irrigations and two irrigations for stress induction). Treatment levels were six populations of the cross under study. Seeds were sown using dibbler and two seeds were placed in each hole. After germination seedlings were thinned out to one seedling per hole. Plant to plant and row to row distance was maintained $15 \mathrm{~cm}$ and $30 \mathrm{~cm}$, respectively. Same agronomic and cultural practices were undertaken for both main plots except irrigation. The trial under normal conditions received four supplementary irrigationswhile trial under drought conditions received two irrigations (one before sowing and second at tillering stage).After rain fall it was possible to drain out water from water stressed experimental plot because of its higher elevation compared to other experimental area.

Data collection: When symptoms of water stress appeared on plants (at the onset of flowering), 10 guarded plants per replication for the parents, $\mathrm{F}_{1}, \mathrm{BC}_{1}$ and $\mathrm{BC}_{2}, 50$ plants per replication for $\mathrm{F}_{2}$ generation were selected to record the data on individual plant basis for following physiological and morphological traits. Stomatal conductance $\left(\mu \mathrm{mol} \mathrm{m} \mathrm{m}^{-2} \mathrm{~s}^{-1}\right)$ and photosynthetic rate $\left(\mu \mathrm{mol} \mathrm{m}{ }^{-2} \mathrm{~s}^{-1}\right)$ were measured using CIRAS-3 Portable Photosystem II. Excised leaf water loss $(\mathrm{g} / \mathrm{g})$ was calculated using formula given by Clarke and McCaig, (1982). Relative water content was calculated using the formula given by Barrs and Weatherley (1962). Plant height $(\mathrm{cm})$, Number of grains per spike and Grain yield per plant (g) were measured using meter rod, electronic counter and weighing balance, respectively.

Statistical analysis:The data was subjected to analysis of variance following the method as outlined by (Steel et al., 1997). Generation means analysis was performed following the method described by Mather and Jinks (1982). Genetic advance was calculated at $10 \%$ selection intensity using formula suggested by Nechif et al. (2011). Narrow sense and broad sense heritability was estimated using formula suggested by Golparvar (2012).

\section{RESULTS AND DISCUSSION}

Generation means were given in Table 1 and frequency distribution of $F_{2}$ population was provided in Figure 1.

Table 1. Generation means for Relative water content (RWC), Excised leaf water loss (ELWL), Photosynthetic rate (PR), stomatal conductance (SC), plant height (PH), number of grains per spike (NGS) and grain yield per plant (GYP) in a cross Chakawal-50 $\times 9436$ under normal $(\mathrm{N})$ and drought $(\mathrm{D})$ conditions in the field.

\begin{tabular}{|c|c|c|c|c|c|c|c|c|}
\hline \multirow[t]{2}{*}{ Traits } & \multirow[t]{2}{*}{ Stress } & \multicolumn{6}{|c|}{ Generations } & \multirow{2}{*}{$\begin{array}{c}\text { Population } \\
\text { effect }\end{array}$} \\
\hline & & $\mathbf{P}_{1}$ & $\mathbf{P}_{2}$ & $F_{1}$ & $\mathbf{F}_{2}$ & $\mathbf{B C}_{1}$ & $\mathrm{BC}_{2}$ & \\
\hline \multirow[t]{2}{*}{ RWC } & $\mathrm{N}$ & 89.6 & 61.1 & 85.6 & 89.2 & 66.5 & 78.6 & $* *$ \\
\hline & $\mathrm{D}$ & 62.9 & 49.3 & 63.9 & 65.2 & 44.0 & 56.6 & $* *$ \\
\hline \multirow[t]{2}{*}{ ELWL } & $\mathrm{N}$ & 3.8 & 6.1 & 4.1 & 4.3 & 5.2 & 4.6 & $* *$ \\
\hline & $\mathrm{D}$ & 1.7 & 3.7 & 1.9 & 2.1 & 3.1 & 2.4 & $* *$ \\
\hline \multirow[t]{2}{*}{ PR } & $\mathrm{N}$ & 30.7 & 25.4 & 29.4 & 30.2 & 26.2 & 27.7 & $* *$ \\
\hline & $\mathrm{D}$ & 29.2 & 23.0 & 27.8 & 29.8 & 25.3 & 27.4 & $*$ \\
\hline \multirow[t]{2}{*}{$\mathrm{SC}$} & $\mathrm{N}$ & 0.7 & 0.5 & 0.7 & 0.7 & 0.6 & 0.6 & $* *$ \\
\hline & $\mathrm{D}$ & 0.7 & 0.6 & 0.7 & 0.7 & 0.6 & 0.6 & $*$ \\
\hline \multirow[t]{2}{*}{$\mathrm{PH}$} & $\mathrm{N}$ & 99.4 & 65.6 & 77.5 & 97.4 & 75.1 & 83.1 & $* *$ \\
\hline & $\mathrm{D}$ & 86.3 & 78.7 & 81.5 & 88.3 & 62.0 & 74.0 & $* *$ \\
\hline \multirow[t]{2}{*}{ NGS } & $\mathrm{N}$ & 68.7 & 56.5 & 68.4 & 70.8 & 62.1 & 66.1 & $* *$ \\
\hline & D & 63.3 & 51.4 & 63.1 & 65.6 & 57.5 & 61.8 & $* *$ \\
\hline \multirow[t]{2}{*}{ GYP } & $\mathrm{N}$ & 25.2 & 16.6 & 26.8 & 25.5 & 19.9 & 22.2 & $* *$ \\
\hline & D & 19.1 & 10.3 & 20.6 & 19.2 & 13.6 & 15.9 & $* *$ \\
\hline
\end{tabular}


Table 2. Estimates of the best fit model for generation means parameters ( \pm , standard error) by weighted least squares analysis in respect for RWC, ELWL, PR, SC, PH, NGS and GYP in a cross Chakawal-50 × 9436 under normal $(\mathrm{N})$ and drought $(\mathrm{D})$ conditions in the field.

\begin{tabular}{|c|c|c|c|c|c|c|c|c|}
\hline \multirow[t]{2}{*}{ Traits } & \multirow[t]{2}{*}{ Stress } & \multicolumn{6}{|c|}{ Genetic Effects } & \multirow[t]{2}{*}{$\chi^{2}(\mathrm{df})$} \\
\hline & & $\mathbf{m} \pm \mathbf{S . E}$ & {$[\mathrm{d}] \pm$ S.E } & {$[\mathbf{h}] \pm \mathbf{S . E}$} & {$[\mathbf{i}] \pm$ S.E } & {$[\mathrm{j}] \pm \mathrm{S} . \mathrm{E}$} & {$[\mathrm{I}] \pm$ S.E } & \\
\hline \multirow{2}{*}{ RWC } & $\mathrm{N}$ & $75.12 \pm 0.25$ & $11.59 \pm 0.26$ & $11.48 \pm 0.47$ & - & - & - & $2.3866(3)$ \\
\hline & $\mathrm{D}$ & $54.97 \pm 0.25$ & $5.41 \pm 0.25$ & $6.91 \pm 0.46$ & - & - & - & $1.3584(3)$ \\
\hline \multirow[t]{2}{*}{ ELWL } & $\mathrm{N}$ & $5.04 \pm 0.09$ & $1.05 \pm 0.09$ & $-0.79 \pm 0.16$ & - & - & - & $1.7900(3)$ \\
\hline & D & $2.97 \pm 0.16$ & $0.96 \pm 0.17$ & $-0.72 \pm 0.29$ & - & $2.21 \pm 1.03$ & - & $0.8770(2)$ \\
\hline \multirow[t]{2}{*}{ PR } & $\mathrm{N}$ & $28.04 \pm 0.15$ & $1.26 \pm 0.14$ & $1.41 \pm 0.77$ & - & - & $-0.08 \pm 0.78$ & $1.2697(2)$ \\
\hline & D & $27.14 \pm 0.14$ & $2.51 \pm 0.13$ & $0.76 \pm 0.75$ & - & - & $0.56 \pm 0.77$ & $0.1613(2)$ \\
\hline \multirow[t]{2}{*}{$\mathrm{SC}$} & $\mathrm{N}$ & $0.78 \pm 0.23$ & $48.49 \pm 0.05$ & $-14.11 \pm 0.28$ & $52.61 \pm 0.24$ & - & - & $0.4498(2)$ \\
\hline & D & $1.04 \pm 0.38$ & $59.49 \pm 0.08$ & $-263.9 \pm 0.43$ & $294.46 \pm 0.39$ & $-252.69 \pm 0.65$ & - & $0.0011(1)$ \\
\hline \multirow[t]{2}{*}{$\mathrm{PH}$} & $\mathrm{N}$ & $81.56 \pm 0.29$ & $8.26 \pm 0.24$ & - & $9.56 \pm 0.39$ & - & - & $0.4303(3)$ \\
\hline & D & $76.85 \pm 0.33$ & $8.28 \pm 0.26$ & - & $10.19 \pm 0.43$ & - & - & $3.5525(3)$ \\
\hline \multirow[t]{2}{*}{ NGS } & $\mathrm{N}$ & $61.74 \pm 0.34$ & $4.88 \pm 0.36$ & $6.60 \pm 0.62$ & - & $-18.36 \pm 2.00$ & - & $1.9465(2)$ \\
\hline & D & $58.05 \pm 0.48$ & $5.65 \pm 0.48$ & $25.40 \pm 2.36$ & - & $-17.20 \pm 2.50$ & $-19.97 \pm 2.43$ & $0.0326(1)$ \\
\hline \multirow[t]{2}{*}{ GYP } & $\mathrm{N}$ & $39.59 \pm 0.81$ & $4.41 \pm 0.09$ & $-42.69 \pm 2.01$ & $-18.72 \pm 0.80$ & - & $29.97 \pm 1.24$ & $0.1764(1)$ \\
\hline & D & $30.85 \pm 1.12$ & $4.23 \pm 0.13$ & $-37.59 \pm 2.54$ & $-16.12 \pm 1.12$ & - & $27.03 \pm 1.49$ & $0.4593(1)$ \\
\hline
\end{tabular}

Generation means analysis was given in Table 2. Heritability and genetic advance were provided in Table 3. Analysis of variance showed that all the traits were revealing significant differences as shown by significant population effect (Table 1).

Table 3. Narrow sense heritability $\left(h^{2}{ }^{2}\right)$, broad sense heritability $\left(\mathrm{h}^{2}\right.$ bs) and genetic advance (GA) for RWC, ELWL, PR, SC, PH, NGS and GYP in cross of Chakawal-50 and 9436 under normal (N) and water stress (D) conditions.

\begin{tabular}{lcccr}
\hline \multirow{2}{*}{ Traits } & Stress & \multicolumn{3}{c}{ Chakawal-50 $\times \mathbf{9 4 3 6}$} \\
\cline { 3 - 5 } & & $\mathbf{h}^{2}$ ns & $\mathbf{h}^{2}$ bs & GA \\
\hline RWC & $\mathrm{N}$ & 0.52 & 0.92 & 19.05 \\
& $\mathrm{D}$ & 0.65 & 0.89 & 14.83 \\
ELWL & $\mathrm{N}$ & 0.57 & 0.90 & 2.86 \\
& $\mathrm{D}$ & 0.56 & 0.87 & 5.55 \\
PR & $\mathrm{N}$ & 0.56 & 0.96 & 4.82 \\
& $\mathrm{D}$ & 0.55 & 0.94 & 4.72 \\
SC & $\mathrm{N}$ & 0.67 & 0.91 & 1.49 \\
& $\mathrm{D}$ & 0.46 & 0.92 & 4.54 \\
PH & $\mathrm{N}$ & 0.76 & 0.96 & 16.67 \\
& $\mathrm{D}$ & 0.54 & 0.96 & 18.01 \\
NGS & $\mathrm{N}$ & 0.45 & 0.80 & 11.22 \\
& $\mathrm{D}$ & 0.45 & 0.85 & 11.92 \\
GYP & $\mathrm{N}$ & 0.56 & 0.89 & 4.62 \\
& $\mathrm{D}$ & 0.56 & 0.92 & 4.76 \\
\hline
\end{tabular}
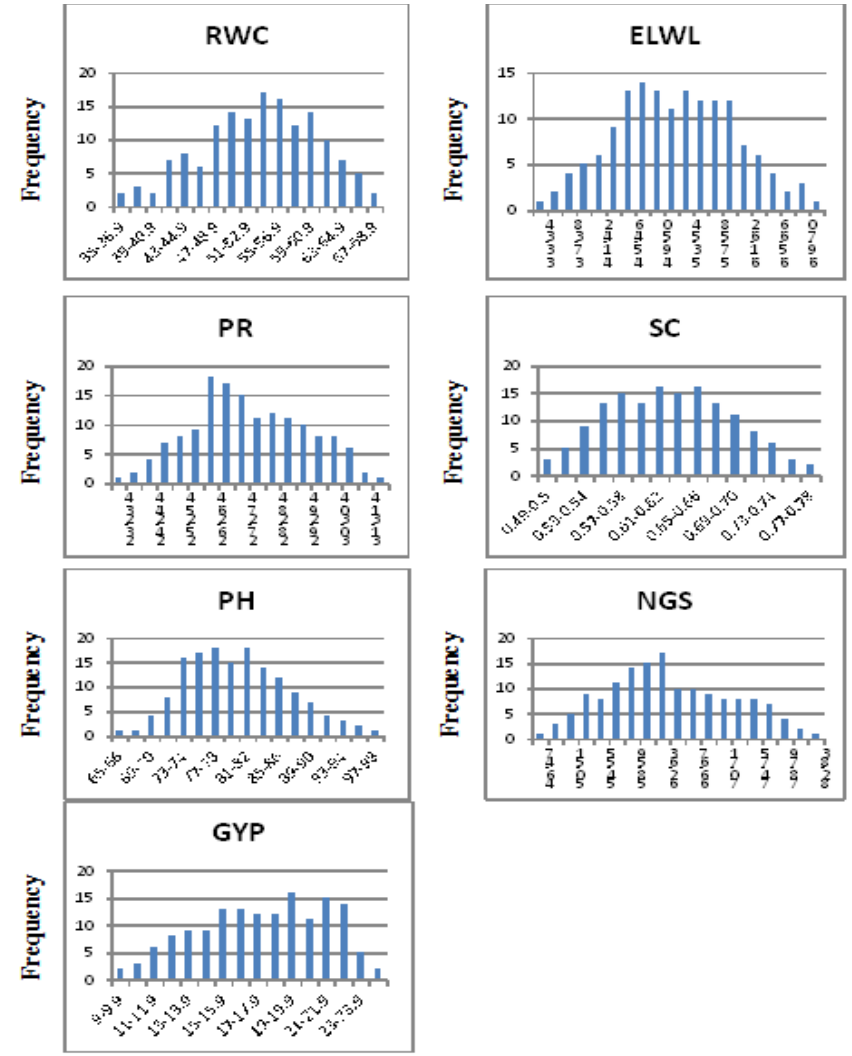

Figure 1. Frequency distribution for RWC, ELWL, PR, SC, PH, NGS and GYP in a cross Chakawal-50 $\times 9436$ under drought conditions in the field. 
Relative water contents:Generation mean analysis showed that this trait was controlled by polygenes. Under both conditions it was controlled by [mdh] showed that there was no significance presence of epistasis for this trait. Additive component was nearly equal to dominance component under both conditions. So finally it can be determined that relative water content was governed by complex inheritance without epistasis was in action under water stress conditions. Delayed selection until 3 or 4 generations should be suggested to get maximum water contents in plants. Similar kind of results were presented in previous researches (Mather and Jinks, 1982; Dhanda and Sethi, 1998; Farshadfar et al., 2001b; Rebetzke et al., 2003a; Farshadfar et al., 2013b; Ijaz et al., 2013 b) while contradictory results were also reported in literature (Golparvar et al., 2006a; Kumar and Sharma, 2007). Narrow sense heritability was found in the range of $0.52-0.67$ while broad sense heritability was in the range of $0.88-0.92$. These results are in accordance with Chandra and Islam (2003), Lugojan and Ciulca (2011) and Jatoi et al. (2012). Genetic advance was found in the range of 14.83-19.05. Genetic advance for this trait was positive and higher showing that $F_{2}$ population could be good source of improving wheat relative water contents. Similar kind of finding were given by Farshadfar et al. (2001b) while contradiction was reported by Said (2014).

It could be concluded that genetic advance was high as well as heritability was also high for this trait. This advocated the presence of additive component in the inheritance of this trait. So it could be concluded that selection from this $F_{2}$ population may result in improvement in this trait.

Excised leaf water loss:Generation mean analysis revealed that this trait was controlled by [mdh] and [mdhj] under normal and water stress conditions, respectively. Additive component was higher than dominance component. While dominance component was negative under stress levels showing that genes which were reducing water loss were acting dominantly over genes which were increasing water loss. Activation of epistatic component under water stress conditions suggested that non-allelic interactions were externally inducible. Finally, it was suggested that ELWL was controlled by complex type of gene action under water stress conditions. Delayed selection until 3 or 4 generations should be suggested to accumulate genes reducing water loss in plants. Similar kind of results were presented by Dhanda and Sethi (1998) and contradictory results were shown by Farshadfar et al. (2001b) and Kumar and Sharma (2007).

The results revealed that narrow sense heritability was $0.54-$ 0.58 while broad sense heritability was $0.86-0.90$. Similar results were given by Lugojan and Ciulca (2011) while contradiction was presented by Chandra and Islam (2003). Genetic advance was estimated 1.95-5.55. Genetic advance for this trait was positive but non-significant showed that $\mathrm{F}_{2}$ population could not be good source for selection of lines with reduced ELWL. Similar findings were also presented by Farshadfar et al. (2001b).

Results revealed that genetic advance was low and heritability was higher. It revealed that non-additive component was involved in inheritance of this trait and hybrid vigor may result in improvement of this trait. Hybrid breeding was suggested for improvement in this trait.

Photosynthetic rate:Generation mean analysis showed that under both conditions this trait was controlled by [mdhl] revealed the importance of epistasis due to presence of dominance $\mathrm{x}$ dominance component [1] of epistasis. Additive component was lower than dominance component under normal conditions while it was higher under stress conditions. It was also suggested that under normal conditions this trait was controlled by duplicate type of epistasis as signs of [h] and [1] were opposite. It was suggested that this trait was governed by complex genetic architecture. Delayed selection was suggested for improvement in this trait. Similar kind of results were presented by Simon (1994) and contradictory results were given by Rebetzke et al. (2006a).

Broad sense heritability was found 0.86 to 0.96 while narrow sense heritability was estimated 0.55 to 0.58 . Reduction in broad sense heritability under water stress showed that environmental components were influencing heritability (Simon, 1994; Rebetzke et al., 2006b). Genetic advance was found 4.3 to 4.8 for this trait. Genetic advance for this trait was positive and non-significant (Zhou et al., 2014).

As shown by high heritability and low genetic advance it was suggested that hybrid vigor may result in improvement of this trait as non-additive gene action was controlling this trait. It was also suggested that non-allelic interactions would also important for this trait as dominance component coupled with epistatic components resulted in non-additive components.

Stomatal conductance: Generation mean analysis showed that this trait was controlled by polygenes. Under normal and water stress conditions it was controlled by [mdhi] and [mdhij] respectively. Additive component was positive and significant while dominance component was negative under both conditions. Negative dominance component showed that genes which were responsible for lowering stomatal conductance were acting dominantly over genes which were increasing this trait. Epistatic component [i] was positive while [j] and [1] were negative and significant. So, it was suggested that this trait was controlled by complex inheritance. Delayed selection to increase stomatal conductance was suggested. Results are in accordance with Rebetzke et al. (2003a) and Farshadfar et al. (2013a) while contradicting results were showed by Clarke (1997) and Farshadfar et al. (2013b).

Broad sense heritability was estimated 0.85-0.96 while narrow sense heritability was estimated 0.46 to 0.67 . Narrow sense heritability was reduced and broad sense heritability was increased under water stress conditions explained the importance and involvement of environmental factor in the 
inheritance of this trait (Jatoi et al., 2012). Genetic advance was estimated 1.5 to 4.5 and positive as well as significant showed that $F_{2}$ population could be a good source of improving wheat stomatal conductance (Estehghari and Farshadfar, 2014).

Results showed that genetic advance and heritability was high revealing that this trait was controlled by additive type of gene action. It could be suggested that selection in this current population may result in improvement of this trait.

Plant height:Generation mean analysis showed that this trait was controlled by polygenes. Under both conditions it was controlled by [mdi]. As dominance component was absent for this trait and additive component was significant so this trait could be explained by additive variance and epistatic components. Only one epistatic component [i] was significant for this trait. This [i] was positive under both conditions meaning that this interaction would result in increase of this trait. This trait was controlled by additive component only so early selection may be suggested for improvement in this trait (Akhtar and Chowdhry, 2006; Rashid et al., 2012) while contradictory results were shown by Novoselovic et al. (2004) and Amin (2006).

Narrow sense heritability was estimated 0.54 to 0.76 while broad sense heritability was estimated 0.89 to 0.96 . Narrow sense heritability was decreased under stress conditions showing that environment had great impact on heritability of this trait. Genetic advance was found medium and in the range of 16.7 to 18.1. Genetic advance for this trait was positive and medium showing that $F_{2}$ population could be good source of improving plant height.

High heritability with low to medium genetic advance was found for this trait. It was suggested that this trait was predominantly controlled by non-additive components. So hybrid breeding could be good source for reducing plant height as hybrid vigor was negative and significant for this trait.

Number of grains per spike:Generation mean analysis showed that this trait was controlled by polygenes. Under normal conditions it was controlled by [mdhj] and under water stress conditions it was controlled by [mdhjl]. Additive component was lower than dominance component under both conditions. Negative signs of [h] and [1] showed that there was presence of duplicate epistasis under stress conditions. Epistatic components were negative under both stress regimes. Finally, it could be concluded that this trait was controlled by complex type of gene action. Selection in later segregating generations would be fruitful for this trait. Similar kind of results were presented by Amin (2006) and Magda and El-Rahman (2013) and contradictory results were shown by Akhtar and Chowdhry (2006) and Gorjanovic and Balalic (2007).

Narrow sense heritability was found $0.45-0.48$ while broad sense heritability was estimated from 0.80 to 0.86 . Genetic advance for this trait was estimated from 11.2 to 12.4 , positive and significant. This may be good source population to select wheat lines with higher number of grains. Opposite results were revealed by Magda and El-Rahman (2013).

Genetic advance were moderate to high for this trait. It could be concluded that additive type genes were more important for this trait. Selection in this population could result in increase of this trait.

Grain yield per plant:Generation mean analysis showed that this trait was controlled by polygenes under both conditions and controlled by [mdhil]. Additive component was higher than dominance component. Dominance component was negative showed that genes which were decreasing grain yield per plant were in general dominance over genes with increasing effect over grain yield per plant. Opposite signs of [h] and [1] showed that this trait was controlled by duplicate epistasis. Selection may be fruitful in later generations for increment in grain yield per plant (Novoselovic et al., 2004; Amin, 2006; Farooq et al., 2011; Ciulca et al., 2012; Ijaz et al., 2013b).

Broad sense heritability was estimated from 0.87 to 0.93 while narrow sense heritability was estimated from 0.53 to 0.58. Genetic advance for this trait was found from 4.5 to 4.8 and non-significant. Similar results were shown by Ijaz et al. (2013a) while contradictory results were shown by Farshadfar et al. (2001b), Badran and Moustafa (2014) and Said (2014). High heritability estimates and low genetic advance shown by this trait under water stress conditions. It could be concluded that non-additive components were more important in inheritance of this trait.

Conclusion:All traits were controlled by complex type of gene action. Heritability and genetic advance estimates were found medium to high. Selection in later generations was suggested to improve wheat cultivars against water stress conditions. Hybrid breeding was suggested for excised leaf water loss and plant height as genetic advance was low and heritability was found higher for these traits. Cultivar Chakawal-50 should be used in further breeding programs. $\mathrm{F}_{2}$ population developed by this cross could be used as a good source population to select improved wheat lines against water stress conditions.

Acknowledgement:Authors acknowledge Higher Education Commission (HEC) Pakistan, for funding this project.

\section{REFERENCES}

Akhtar, N. and M.A. Chowdhry. 2006. Genetic analysis of yield and some other quantitative traits in bread wheat. Int. J. Agric. Biol. 8:523-527.

Akram, Z., S.U. Ajmal and M. Munir. 2008. Estimation of correlation coefficient among some yield parameters of wheat under rainfed conditions. Pak. J. Bot. 40:17771781 . 
Ali, Y., B.M. Atta, J. Akhter, P. Monneveux and Z. Lateef. 2008. Genetic variability, association and diversity studies in wheat (Triticum aestivum L.) germplasm. Pak. J. Bot. 40:2087-2097.

Amin, I.A. 2006. Genetic behaviour of some agronomic traits in two durum wheat crosses under heat stress. Alex. J. Agric. Res. 58:53-66.

Badran, A.E. and E.S.A. Moustafa. 2014. Genetic parameters of some wheat (Triticum aestivum L.) genotypes using factorial mating design. J. Agric. Sci. 7:101-105.

Barrs, H.D. and P.E. Weatherley. 1962. A re-examination of the relative turgidity technique for estimating water deficits in leaves. Aust. J. Biol. Sci. 15:413-428.

Chandra, D. and M.A. Islam. 2003. Genetic variation and heritability of excised-leaf water loss and its relationship with yield and yield components of $f 5$ bulks in five wheat crosses. J. Biol. Sci. 3:1032-1039.

Chandrasekar, V., R.K. Sairam and G.C. Srivastava. 2000. Physiological and biochemical responses of hexaploid and tetraploid wheat to drought stress. J. Agron. Crop Sci. 185:219-227.

Ciulca, S., C. Adriana, E. Madosa and V. Giancarla. 2012. Genetic analysis for plant yield in winter wheat. J. Hortic. For. Biotechnol. 16:78-81.

Clarke, J.M. 1997. Inheritance of stomatal conductance in a durum wheat cross. Can. J. Plant Sci. 77:623-625.

Clarke, J.M. and T.N. McCaig. 1982. Excised-leaf water retention capability as an indicator of drought resistance of Triticum genotypes. Can. J. Plant Sci. 62:571-578.

Condon, A.G., G.D. Farquhar and R.A. Richards. 1990. Genotypic variation in carbon isotope discrimination and transpiration efficiency in wheat: Leaf gas exchange and whole plant studies. Funct. Plant Biol. 17:9-22.

Dhanda, S.S. and G.S. Sethi. 1998. Inheritance of excised-leaf water loss and relative water content in bread wheat (Triticum aestivum). Euphytica 104:39-47.

Estehghari, M.R. and E. Farshadfar. 2014. Evaluation of phenotypic variability, genetic parameters, heritability and genetic gain in bread wheat genotypes under rainfed conditions. Int. J. Biosci. 4:193-201.

FAO. 2015. FAOSTAT. Available online at Faostat.fao.org

Farooq, J., I. Khaliq, M. Kashif, Q. Ali and S. Mahpara. 2011. Genetic analysis of relative cell injury percentage and some yield contributing traits in wheat under normal and heat stress conditions. Chilean J. Agric. Res. 71:511-520.

Farshadfar, E., M. Farshadfar and J. Sutka. 2001a. Combining ability analysis of drought tolerance in wheat over different water regimes. Acta Agron. Hung. 48:353-361.

Farshadfar, E., Ghanadha, J. Sutka and M. Zahravi. 2001b. Generation mean analysis of drought tolerance in wheat (Triticum aestivum L.). Acta Agron. Hung. 49:59-66.

Farshadfar, E., M. Allahgholipour, L. Zarei and M. Kiani. 2013a. Genetic analysis of field and physiological indicators of drought tolerance in bread wheat (Triticum aestivum L.) using diallel mating design. Afr. J. Biotechnol. 10:13071-13081.

Farshadfar, E., F. Rafiee and H. Hasheminasab. 2013b. Evaluation of genetic parameters of agronomic and morpho-physiological indicators of drought tolerance in bread wheat (Triticum aestivum L.) using diallel mating design. Aust. J. Crop Sci. 7:268-275.

Golparvar, A.R. 2012. Heritability and mode of gene action determination for grain filling rate and relative water content in hexaploid wheat. Genetika 44:25-32.

Golparvar, A.R., A. Ghasemi-Pirbalouti and H. Madani. 2006a. Genetic control of some physiological attributes in wheat under drought stress conditions. Pak. J. Biol. Sci 9:1442-1446.

Golparvar, A.R., A.G. Pirbalouti and H. Madani. 2006b. Genetic control of some physiological attributes in wheat under drought stress conditions. Pak. J. Biol. Sci. 9:4421446.

Gorjanovic, B.M. and M.M.K. Balalic. 2007. Inheritance of plant height, spike length and number of spikelets per spike in durum wheat. Proc. Nat. Sci, MaticaSrpska Novi Sad. 112:27-33.

Ijaz, F., I. Khaliq, M.T. Shahzad and B. Saleem. 2013a. Computation of heritability of yield and some morphological traits in $\mathrm{F}_{2}$ populations of spring wheat (Triticum aestivumL.). Int. J. Mod. Agric. 2:102-107.

Ijaz, U., Smiullah and M. Kashif. 2013b. Generation means analysis for five physiological traits of bread wheat under rainfed condition. Univ. J. Plant Sci. 1:21-26.

Jatoi, W.A., M.J. Baloch, M.B. Kumbhar and M.I. Keerio. 2012. Heritability and correlation studies of morphophysiological traits for drought tolerance in spring wheat. Pak. J. Agric. Agril. Engg. Vet. Sci. 28:100-114.

Khan, A.S., M. Ashfaq and M.A. Asad. 2003. A correlation and path coefficient analysis for some yield components in bread wheat. Asian J. Plant Sci. 2:582-584.

Khan, A.S., M. Khan, R. Kashif and T.M. Khan. 2000. Genetic analysis of plant height, grain yield and other traits in wheat (Triticum aestivum L.). Int. J. Agric. Biol. 2:129-132.

Kumar, A. and S. Sharma. 2007. Genetics of excised-leaf water loss and relative water content in bread wheat (Triticum aestivum L.). Cereal Res. Commun. 35:43-52.

Lugojan, C. and S. Ciulca. 2011. Analysis of excised leaves water loss in winter wheat. J. Hortic. For. Biotechnol. 15:178-182.

Magda, E. and A.B. El-Rahman. 2013. Estimation of some genetic parameters through generation mean analysis in three bread wheat crosses. Alex. J. Agric. Res. 58:183195.

Mather, K. and J.L. Jinks. 1982. The Study of Continuous Variation, $1^{\text {st }}$ Ed. Chapman and Hall, London, UK.

Nechif, O.R., R.B. Filimon and L. Szilagyi. 2011. Genetic variability, heritability and expected genetic advance as 
indices for yield and yield components selection in common bean (Phaseolus vulgaris L.). Scientific Papers, UASVM Bucharest, Series A 7:332-337.

Novoselovic, D., M. Baric, G. Drezner, J. Gunjaca and A. Lalic. 2004. Quantitative inheritance of some wheat plant traits. Genet. Mol. Biol. 27:92-98.

Rashid, M.A.R., A.S. Khan and R. Iftikhar. 2012. Genetic studies for yield and yield related parameters in bread wheat. Am-Eur. J. Agric. Environ. Sci. 12:1579-1583.

Rauf, M., M. Munir, M. Hassan, M. Ahmad and M. Afzal. 2007. Performance of wheat genotypes under osmotic stress at germination and early seedling growth stage. Afr. J. Biotechnol. 6:971-975.

Rebetzke, G., A. Condon, R. Richards and G. Farquhar. 2003a. Gene action for leaf conductance in three wheat crosses. Crop Pasture Sci. 54:381-387.

Rebetzke, G.J., A.G. Condon, R.A. Richards and G.D. Farquhar. 2003b. Gene action for leaf conductance in three wheat crosses.Crop Pasture Sci. 54:381-387.

Rebetzke, G., R. Richards, A. Condon and G. Farquhar. 2006a. Inheritance of carbon isotope discrimination in bread wheat (Triticum aestivum L.). Euphytica 150:97106.

Rebetzke, G.J., R.A. Richards, A.G. Condon and G.D. Farquhar. 2006b. Inheritance of carbon isotope discrimination in bread wheat (Triticum aestivum L.). Euphytica 150:97-106.

Reddy, A.R., K.V. Chaitanya and M. Vivekanandan. 2004. Drought-induced responses of photosynthesis and antioxidant metabolism in higher plants. J. Plant Physiol. 161:1189-1202.

Said, A.A. 2014. Generation mean analysis in wheat (Triticum aestivum L.) under drought stress conditions. Ann. Agric. Sci. 59:177-184.

Simon, M.R. 1994. Gene action and heritability for photosynthetic activity in two wheat crosses. Euphytica 76:235-238.

Steel, R.G.D., J.H. Torrie and D.A. Dickey. 1997. Principles and Procedures of Statistics: A biological approach, $3^{\text {rd }}$ Ed. McGraw-Hill Book Co. New York, USA.

Tonk, F.A., E. Ilker and M. Tosun. 2011. Quantitative inheritance of some wheat agronomic traits. Bulgarian J. Agric. Sci. 17:783-788.

Ullah, S., A.S. Khan, A. Raza and S. Sadique. 2010. Gene action analysis of yield and yield related traits in spring wheat (Triticum aestivum). Int. J. Agric. Biol. 12:125128.

Visscher, P.M., W.G. Hill and N.R. Wray. 2008. Heritability in the genomics era-concepts and misconceptions. Nat. Rev. Genet. 9:255-266.

Vorosmarty, C.J., P. Green, J. Salisbury and R.B. Lammers. 2000. Global water resources: Vulnerability from climate change and population growth. Sci. 289:284-288.

Zhou, B., A.S. Saez, A. Elazab, T. Shen, R.S. Bragado, J. Bort, M.D. Serret and J.L. Araus. 2014. Physiological traits contributed to the recent increase in yield potential of winter wheat from Henan Province, China. J. Integr. Plant Biol. 56:492-504. 